\title{
Immunological status in patients undergoing in vitro fertilisation: responses to hormone treatment and relation SHIP to outcome
}

\author{
Marie Persson, Christina Ekerfelt, Barbara Jablonowska, Yvonne Jonsson, Jan Ernerudh, \\ Maria C. Jenmalm and Göran Berg
}

\section{Linköping University Post Print}

\begin{abstract}
N.B.: When citing this work, cite the original article.
\end{abstract}
Original Publication:

Marie Persson, Christina Ekerfelt, Barbara Jablonowska, Yvonne Jonsson, Jan Ernerudh, Maria C. Jenmalm and Göran Berg, Immunological status in patients undergoing in vitro fertilisation: responses to hormone treatment and relation SHIP to outcome, 2012, American Journal of Reproductive Immunology, (96), 1-2, 58-67.

http://dx.doi.org/10.1016/j.jri.2012.07.005

Copyright: John Wiley and Sons http://www.wiley.com/

Postprint available at: Linköping University Electronic Press http://urn.kb.se/resolve?urn=urn:nbn:se:liu:diva-85640 
IMMUNOLOGIC STATUS IN PATIENTS UNDERGOING IN VITRO FERTILIZATION:

RESPONSES TO HORMONE TREATMENT AND RELATIONSHIP TO OUTCOME

Marie Persson, B.Sc ${ }^{\mathrm{a}}$

Christina Ekerfelt, Ph.D ${ }^{\mathrm{a}}$

Barbara Jablonowska, M.D, Ph.D. ${ }^{\mathrm{b}}$

Yvonne Jonsson, Ph.D. ${ }^{\text {a }}$

Jan Ernerudh, M.D, Ph.D. ${ }^{\text {a }}$

Maria C Jenmalm, Ph.D. ${ }^{a}$

Göran Berg, M.D, Ph.D. ${ }^{\text {b }}$

${ }^{a}$ Division of Inflammation Medicine, Department of Clinical and Experimental Medicine,

Faculty of Health Sciences, Linköping University, Linköping, Sweden

${ }^{\mathrm{b}}$ Division of Obstetrics and Gynecology, Department of Clinical and Experimental Medicine,

Faculty of Health Sciences, Linköping University, Linköping, Sweden

Corresponding author:

Marie Persson, B.Sc.

$\triangle$ AIR, Pathology Building, Floor 10, Division of Inflammation Medicine, Department of Clinical and Experimental Medicine, Faculty of Health Sciences, University of Linköping, SE-581 85 Linköping, Sweden

$\oplus$ marie.h.persson@liu.se 


\begin{abstract}
We aimed to prospectively investigate the paternal antigen-induced cytokine secretion by peripheral blood mononuclear cells (PBMC) in response to hormone treatment in women undergoing in vitro fertilization (IVF) and to examine the predictive value of the cytokine secretion in the outcome of IVF treatment in a pilot study. Twenty-five women were included and IVF treatment was successful for six and unsuccessful for 19 women. Blood samples were collected before IVF treatment, on four occasions during IVF and 4 weeks after embryo transfer. The numbers of Th1-, Th2- and Th17-associated cytokine secreting cells and cytokine levels in cell supernatants were analyzed by enzyme linked immunospot-forming (ELISpot), enzyme-linked immune-sorbent (ELISA) or Luminex assay. None of the cytokines (IFN- $\gamma$, IL-4, IL-5, IL-10, IL-12, IL-13, IL-17, TNF and GM-CSF) had any predictive value regarding IVF outcome. The majority of the cytokines reached their peak levels at ovum pickup, suggesting an enhancing influence of the hormonal stimulation. Pregnancy was associated with a high number of IL-4-, IL-5- and IL-13-secreting cells four weeks after ET. In conclusion, the results do not support our hypothesis of a more pronounced peripheral Th1 and Th17 deviation towards paternal antigens in infertile women with an unsuccessful IVF outcome, although this is based on a small number of observations. Thus, a larger study should be conducted to confirm this conclusion. Higher numbers of Th2-associated cytokinesecreting cells in pregnant women four weeks after ET do corroborate the hypothesis of a Th2 deviation during pregnancy.
\end{abstract}

Key Words: IVF, Th1, Th2, Th17, immune regulation 


\section{Introduction}

The immune system plays a role in the aetiology of infertility and in successful implantation (Simon et al., 1998; Sanchez-Cuenca et al., 1999; Ng et al., 2002; Inagaki et al., 2003; Kwak-Kim et al., 2003; Ledee-Bataille et al., 2004a; Ledee-Bataille et al., 2004b; Boomsma et al., 2009). T helper (Th) cells regulate and deviate immune responses through cytokine production. Th1 cells produce interferon-gamma (IFN- $\gamma$ ) and lymphotoxin, while the Th2 subset is the source of interleukin (IL) 4, IL-5, IL-13, IL-25 and IL-31. Both subsets produce granulocyte macrophage colony-stimulating factor (GM-CSF), TNF, IL-2 and IL-3 (Commins et al., 2010).

A Th2 bias has been observed during normal pregnancy (Lin et al., 1993; Wegmann et al., 1993; Ekerfelt et al., 1997; Sacks et al., 2003). Serum IFN- $\gamma$ levels were increased in women with unexplained recurrent spontaneous miscarriages (Raghupathy et al., 1999). Several similar studies indicate a Th1 bias among women with pregnancy losses, whereas successful pregnancies are associated with increased Th2 responses (Piccinni et al., 1998; Makhseed et al., 2001; Kwak-Kim et al., 2003; Kalu et al., 2008; Hudic and Fatusic, 2009). High levels of the anti-inflammatory cytokine IL-10 are also associated with improved pregnancy outcomes (Wu et al., 2001; Ginsburg et al., 2005).

The Th1/Th2 paradigm has now been expanded into the Th1/Th2/Th17 and regulatory $\mathrm{T}$ (Treg) cell paradigm. Th17 cells are pro-inflammatory IL-17 secreting cells (Milner, 2011). Tregs induce tolerance by several mechanisms (Peterson, 2012), including IL-10 production. Unexplained recurrent miscarriage has been associated with decreased Treg and increased Th17 frequencies (Wang et al., 2010b; Ernerudh et al., 2011), as well as a decreased suppressive ability by Tregs on IL-17 secretion (Wang et al., 2010a).

Although increased Th1 and Th17 responses in women with recurrent pregnancy loss have been observed, paternal PBMC have, to our knowledge, not been used as a stimulus to 
examine the maternal immune responses toward fetal antigens before. Strong mitogenic stimuli such as PMA/ionomycin (Piccinni et al., 1998; Kwak-Kim et al., 2003; Sacks et al., 2003; Kalu et al., 2008) or PHA (Makhseed et al., 2001), as well as trophoblast cell line extracts (Raghupathy et al., 1999; Ginsburg et al., 2005) have previously been used as stimuli, whereas we here wanted to investigate paternal antigen-induced responses during in vitro fertilization (IVF) treatment.

We hypothesized that an unsuccessful outcome of IVF treatment in infertile women would be related to a paternal antigen specific Th1 and Th17 bias and that differences in the cytokine responses would predict the IVF outcome. The aim of this pilot study was to analyze the spontaneous and paternal antigen-induced cytokine responses from peripheral blood mononuclear cells (PBMC) of women undergoing IVF and to examine the predictive value of the cytokine secretion in the outcome of IVF. Cytokines associated with Th1 (IFN- $\gamma$ and IL12), Th2 (IL-4, IL-5 and IL-13) and Th17 (IL-17) responses, as well as the pro-inflammatory cytokines TNF and GM-CSF and the anti-inflammatory cytokine IL-10 were studied.

\section{Materials and methods}

\subsection{Subjects}

Twenty-five IVF patients with unexplained infertility (age 25-37 years, median 32.5 years) were enrolled prospectively. Infertility was defined as the failure to conceive after twelve months of regular unprotected sexual intercourse. All couples underwent standard investigations aimed to evaluate infertility including laboratory assessment of ovulation (the measurement of mid-luteal progesterone concentration in plasma), evaluation of tubal patency (by hysterosalpingography and/or laparoscopy) and semen analysis. Only couples with no apparent reason for their infertility (suffering from unexplained infertility) were included in the study. The women were all undergoing IVF treatment at the Reproductive Medicine 
Centre, Department of Obstetrics and Gynecology at The University Hospital in Linköping, Sweden. Informed consent was obtained and the study was approved by the Regional Ethics Committee at Linköping University.

\subsection{Ovarian stimulation protocol}

The women were desensitized with the GnRH agonists busereline acetate (Suprecur; sanofi-aventis AB, Bromma, Sweden), $900 \mu \mathrm{g}$ daily, or nafareline acetate (Synarela; Pfizer, Sollentuna, Sweden), $800 \mu \mathrm{g}$ daily, started on cycle day 21 until the day of HCG injection. Ovarian stimulation was carried out using the recombinant FSH follitrophin alpha (Gonal F; Serono Nordic AB, Stockholm, Sweden), 150 IU daily, or follitrophin beta (Puregon; Organon AB, Göteborg, Sweden), 150 IU daily, administered at approximately 10-12 days in combination with a lower dosage of $\mathrm{GnRHa}(450 \mu \mathrm{g}$ of busereline acetate or $400 \mu \mathrm{g}$ of nafareline acetate daily). HCG was administered (10 000 IU) (Profasi; Serono Nordic AB, Stockholm, Sweden) when a minimum of two follicles had reached at least $18 \mathrm{~mm}$ in diameter. $36 \mathrm{~h}$ after HCG administration, ovum pick up (OPU) was performed by transvaginal ultrasound-guided puncture. Luteal support was given using progesterone vaginally (Progesteron MIC; Apoteket AB, Stockholm, Sweden), $1200 \mathrm{mg}$ daily for 20 days, starting on the day of OPU. High quality embryos were defined by their morphologic features and cleavage rate and included embryos with less than $20 \%$ fragmentation and 4 to 6 cells at day 2, 6 to 10 cells at day 3. Embryo transfer was only performed two or three days after oocyte retrieval.

\subsection{Collection of samples}

Blood samples from the women were obtained on six different occasions in the stimulatory cycle protocol: a) prior to hormonal stimulation on cycle day $1-5 ;$ b) two weeks after GnRHa administration; c) approximately day 10 during FSH stimulation; d) at the time 
of OPU; e) at the time of ET; and f) four weeks after ET (Fig. 1). Blood samples from the women's partners were collected on the first occasion.

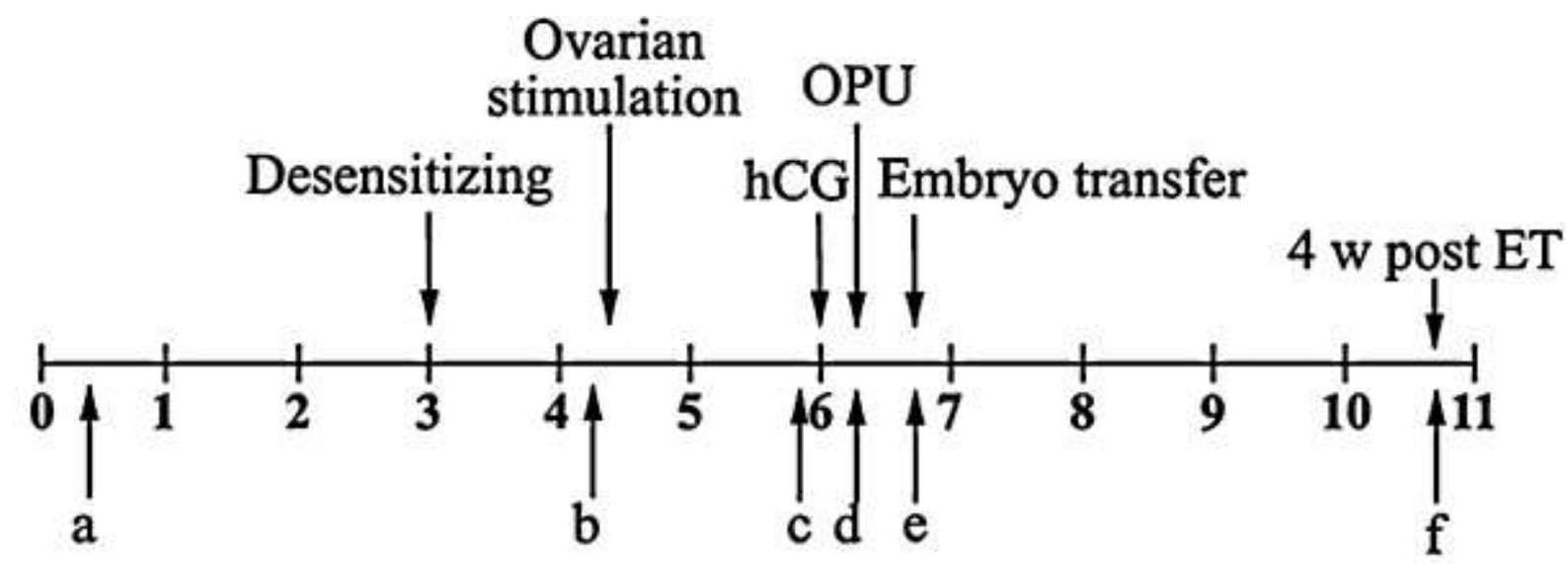

Estradiol

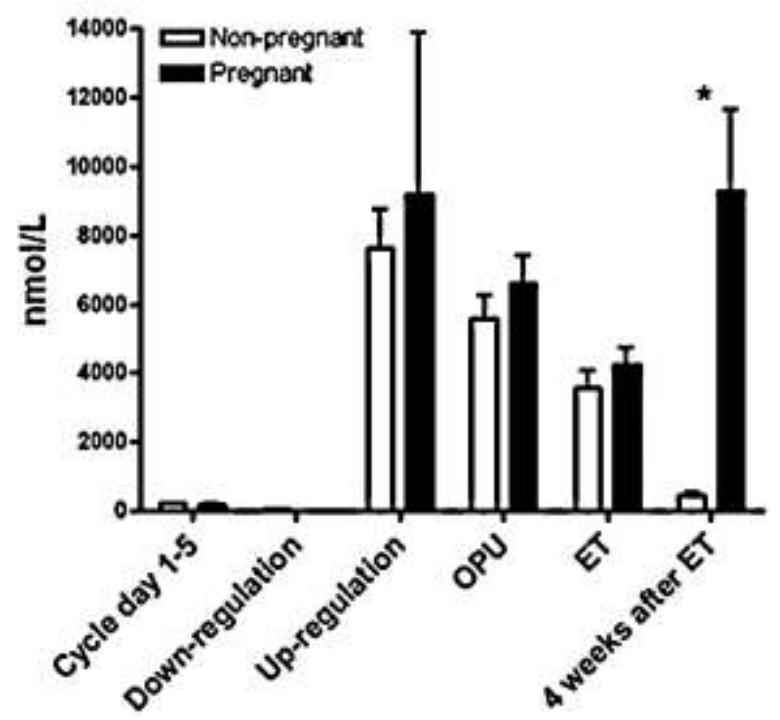

Progesterone

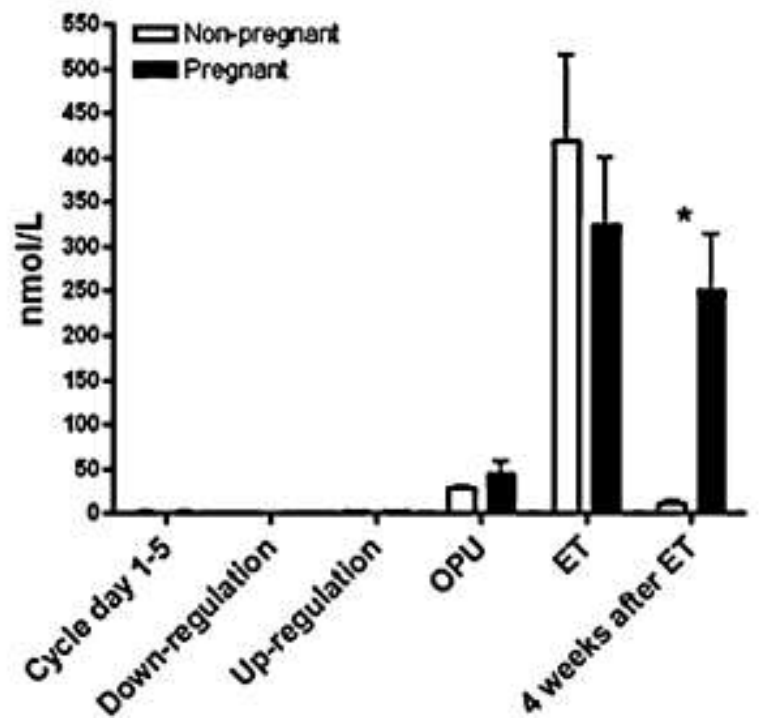

Fig. 1. Timeline shows the collection of samples (a-f) during the stimulatory cycle protocol and the levels of $\mathrm{E}_{2}$ and $\mathrm{P}$ at each occasion. $0-11=$ number of weeks. $p<0.05$ from Mann Whitney U test is indicated (*).

\subsection{Separation of PBMC}

PBMC were isolated from heparinized blood and frozen as previously described (Persson et al., 2008). PBMC from the fathers-to-be (paternal cells) were isolated according to the same protocol as the PBMC from the mothers-to-be (maternal cells).

\subsection{Inhibition of stimulator cells}


The stimulator cells, i. e. paternal PBMC, were treated with $4 \%$ paraformaldehyde (PFA; Merck Eurolab AB, Stockholm, Sweden) in phosphate-buffered saline (PBS; EC Diagnostics AB, Uppsala, Sweden) for 10 minutes at room temperature (RT) to inhibit cytokine secretion (Ekerfelt et al., 1997).

\subsection{MLC - ELISpot}

The alloreactivity and cytokine secrection from responder cells was determined by using a one way mixed leukocyte culture (MLC) as previously described (Ekerfelt et al., 1997; Persson et al., 2008). Nitrocellulose-bottomed 96-well microtiter plates (Millipore AB, Sundbyberg, Sweden) were incubated with $100 \mu \mathrm{L}$ of mouse anti-human IFN- $\gamma$ 1-D1K monoclonal antibody (mAb), mouse anti-human IL-4-I mAb, mouse anti-human IL-5 TRFK5 mAb, mouse anti-human IL-12-I mAb or mouse anti-human IL-13-I mAb (all antibodies from MabTech AB, Stockholm, Sweden) at a final concentration of $15 \mu \mathrm{g} / \mathrm{mL}$.

For the detection of paternal antigen-induced secretion of IFN- $\gamma$, IL-4 and IL-5, responder cells were mixed with PFA-treated paternal stimulator cells. Spontaneous secretion of IFN- $\gamma$, IL-4, IL-5, IL-12 and IL-13 was determined by mixing responder cells with TCM containing 5\% FCS. The numbers of paternal antigen-induced IFN- $\gamma$-, IL-4- and IL-5secreting cells were found to be higher than the number of spontaneously secreting cells. For IFN- $\gamma$, this was observed at all occasions, for IL-4 at all times except cycle day 1-5, and for IL-5 at all times except cycle day 1-5 and four weeks after ET.

For the enumeration of cytokine secreting cells, enzyme-linked immunospot-forming assay (ELISpot) was performed as previously described (Persson et al., 2008). The biotinylated detection antibodies were anti-human IFN- $\gamma$ 7-B6-1 mAb, anti-human IL-4-II mAb, anti-human IL-5 5A10 mAb, anti-human IL-12-III mAb or anti-human IL-13-II mAb (all antibodies from MabTech AB, Stockholm, Sweden) diluted to $1 \mu \mathrm{g} / \mathrm{mL}$ in PBS-Tween. 
The spots were counted using the ELISpot reader system Transtec 1300 (Autoimmune Diagnostica GmbH, Strasburg, Germany).

\subsection{MLC - supernatants}

One-way MLC was performed in polypropylene tubes. Briefly, 0.8 x $10^{6}$ responder PBMC (maternal cells) in $800 \mu \mathrm{L}$ of complete medium was co-cultured with $0.8 \times 10^{6}$ PFA-treated paternal PBMC in $800 \mu \mathrm{L}$ of complete medium, in replicates of three. The cultures were incubated for 3 days for TNF and 7 days for the remaining cytokines at $37^{\circ} \mathrm{C}$ in a $5 \% \mathrm{CO}_{2}$ atmosphere.

\subsection{Determination of cytokine concentrations}

Supernatants were analyzed by Milliplex ${ }^{\mathrm{TM}}$ MAP kits (Millipore Corporation, Billerica, USA) according to the manufacturer's instructions using the Luminex 100 instrument (Biosource, Nivelles, Belgium). StarStation software (version 2.3; Applied Cytometry Systems, Sheffield, UK) was used for acquisition and analysis of data. The range of the standard curves was 3.2-10000 pg/mL for IFN- $\gamma ; 3.2-2000 \mathrm{pg} / \mathrm{mL}$ for IL-10; and $0.64-2000$ $\mathrm{pg} / \mathrm{mL}$ for IL-4, IL-12, IL-17 and GM-CSF, with a dilution factor of 5. The levels of TNF were determined using enzyme-linked immunosorbent assay (ELISA) as previously described (Böttcher et al., 2003) and the range of the standard curve was 1.9-125.0 pg/mL. Values below the detection limit were given half the value of the detection limit.

\subsection{Progesterone and estradiol in serum}

Thawed serum samples from all occasions were analysed in one batch, for $\mathrm{P}$ with competitive chemoluminescent immunoassay (Immulite, DPC, Los Angeles, CA) and for $\mathrm{E}_{2}$ with electrochemiluminescence immunoassay (Elecsys 2010; Modular E170, Roche Diagnostics Scandinavia AB, Bromma, Sweden), at the Department of Clinical Chemistry, 
Center of Laboratory Medicine, Linköping University Hospital, Sweden. The range of the P assay was $0.6-127 \mathrm{nmol} / \mathrm{L}$ and the sensitivity was $0.3 \mathrm{nmol} / \mathrm{L}$. The range of the $\mathrm{E}_{2}$ assay was 18-15 $780 \mathrm{pmol} / \mathrm{L}$ and the sensitivity $44 \mathrm{pmol} / \mathrm{L}$.

\subsection{Statistics}

All data were analyzed with SPSS (SPSS Inc., Chicago, Illinois, USA). Patient's characteristics were analysed using Fisher exact test or Student's t-test, depending on the type of variable (continuous or categorical).

Logistic regression was performed, using the independent variables (i.e. the number of IFN- $\gamma$-, IL-4-, IL-5-, IL-12- and IL-13-secreting cells or the levels of IFN- $\gamma$, IL-4, IL-10, IL12, IL-17, GM-CSF and TNF) to predict the presence or absence of pregnancy and to estimate odds ratios for each of the independent variables in the model.

Comparison of the cytokine responses and serum levels of $\mathrm{P}$ and $\mathrm{E}_{2}$ between the two groups of women (pregnant versus non-pregnant) was done using Mann Whitney U test.

Wilcoxon signed ranks test was used to compare the spontaneous and paternal antigeninduced secretion over time in all subjects, regardless of IVF outcome.

Fold change was calculated by comparing the number of cytokine secreting cells or the cytokine levels at each sample occasion (down-regulation, up-regulation, OPU, ET and four weeks after ET) to the first occasion (cycle day 1-5). Wilcoxon signed ranks test was used to compare the changes over time in all subjects, and the comparison between pregnant and nonpregnant women was made with Mann Whitney U test.

\section{Results}

\subsection{Patients}


The 25 women included in the study were classified as pregnancy failures $(n=18)$, clinical pregnancies (successful full term pregnancies) $(n=6)$ and biochemical pregnancies $(n=1)$. The women in the pregnancy failure group had a higher mean age than the women in the clinical pregnancy group (table 1). Mean number of smokers, length of menstrual cycle, gravidity/parity and length of infertility were all comparable in the three different groups, as were the mean FSH levels on cycle day 3, initial FSH dose and total FSH dose. There were no differences in the mean number of collected oocytes, fertilized oocytes, high quality embryos, transferred embryos and frozen embryos between the groups. Higher levels of both $\mathrm{P}$ and $\mathrm{E}_{2}$ were observed in the pregnant group than the non-pregnant group four weeks after ET (Fig. 1).

\subsection{Cytokine secretion in relation to IVF outcome}

At the time of OPU, the number of spontaneously IL-5-secreting cells was lower in the group of women that became pregnant compared with the group that did not. Four weeks after ET, on the other hand, the pregnant women showed a higher number of IL-13-secreting cells than the non-pregnant women (Fig. 2). The number of spontaneously IFN- $\gamma-$, IL-4- and IL-12secreting cells was similar in the two groups at all time points.

The number of paternal antigen-induced IL-4- and IL-5-secreting cells was higher among the pregnant than the non-pregnant women four weeks after ET (Fig. 3). However, at the time of OPU the number of paternal antigen-induced IL-5-secreting cells was higher in the non-pregnant group. Also, the paternal antigen-induced IL-4 secretion was higher in the nonpregnant than the pregnant group at cycle day 1-5 (Fig. 3). The number of paternal antigeninduced IFN- $\gamma$-secreting cells and the IFN- $\gamma$, IL-10, IL-12, IL-17, GM-CSF and TNF levels were similar in the two groups at all occasions. 


\section{Table 1. Characteristics of IVF patients}

\begin{tabular}{|c|c|c|c|c|c|}
\hline & $\begin{array}{c}\text { Total } \\
\text { population } \\
n=24\end{array}$ & $\begin{array}{c}\text { Pregnancy } \\
\text { failure } \\
n=17\end{array}$ & $\begin{array}{c}\text { Clinical } \\
\text { pregnancy } \\
n=6\end{array}$ & $\begin{array}{c}\text { Biochemical } \\
\text { pregnancy } \\
n=1\end{array}$ & $p$ value \\
\hline Age (years) & $32.3 \pm 3.1$ & $33.4 \pm 2.3$ & $29.1 \pm 2.9$ & 27.5 & $<.01^{\mathrm{a}}$ \\
\hline Body mass index $\left(\mathrm{kg} / \mathrm{m}^{2}\right)$ & $23.2 \pm 2.9$ & $23.2 \pm 2.9$ & $21.9 \pm 1.9$ & 28.7 & NA \\
\hline Smoking (\%) & 21 & 17.6 & 16.7 & 100 & NS \\
\hline Menstrual cycle (days) & $28.0 \pm 2.9$ & $28.2 \pm 2.5$ & $27.3 \pm 5.0$ & 30.0 & NS \\
\hline \multicolumn{6}{|l|}{ Gravidity (\%) } \\
\hline 0 & 79 & 82.4 & 83.3 & 0 & NS \\
\hline 1 & 21 & 17.6 & 16.7 & 100 & NS \\
\hline \multicolumn{6}{|l|}{ Parity (\%) } \\
\hline 0 & 95.8 & 100 & 100 & 0 & NS \\
\hline 1 & 4.2 & 0 & 0 & 100 & NS \\
\hline Duration of infertility (years) & $3.6 \pm 1.4$ & $3.7 \pm 1.4$ & $2.9 \pm 0.7$ & 4.0 & NS \\
\hline FSH level, cycle day 3 (pmol/L) & $6.3 \pm 1.8$ & $6.4 \pm 1.7$ & $5.9 \pm 2.1$ & 4.5 & NS \\
\hline \multicolumn{6}{|l|}{ GnRH agonist (\%) } \\
\hline Synarela & 16.7 & 17.6 & 16.7 & 0 & NS \\
\hline Supcrecur & 83.3 & 82.4 & 83.3 & 100 & NS \\
\hline \multicolumn{6}{|l|}{ FSH agonist (\%) } \\
\hline Puregon & 54.2 & 58.8 & 50 & 0 & NS \\
\hline Gonal F & 45.8 & 41.2 & 50 & 100 & NS \\
\hline FSH, initial dose (IU) & $178.6 \pm 70.3$ & $176.3 \pm 62.2$ & $158.3 \pm 20.4$ & 150.0 & NS \\
\hline FSH, total dose (IU) & $1988.2 \pm 794.9$ & $1981.0 \pm 693.6$ & $1729.2 \pm 417.3$ & 1650.0 & NS \\
\hline \multicolumn{6}{|l|}{ Number of oocytes } \\
\hline Collected & $11.8 \pm 4.7$ & $11.6 \pm 4.7$ & $12.5 \pm 3.7$ & 16.0 & NS \\
\hline Fertilized & $8.8 \pm 4.1$ & $8.2 \pm 4.5$ & $9.7 \pm 3.3$ & 12.0 & NS \\
\hline \multicolumn{6}{|l|}{ Number of embryos } \\
\hline High quality & $4.0 \pm 2.7$ & $3.4 \pm 2.5$ & $5.3 \pm 3.0$ & 7.0 & NS \\
\hline \multicolumn{6}{|l|}{ Transferred (\%) } \\
\hline 1 & 83 & 88 & 83 & 0 & \\
\hline 2 & 17 & 12 & 17 & 100 & NA \\
\hline Frozen & $2.83 \pm 2.5$ & $2.2 \pm 2.1$ & $4.2 \pm 3.2$ & 5.0 & NS \\
\hline \multicolumn{6}{|l|}{ Pregnancy outcome (\%) } \\
\hline Positive & 29 & & & & \\
\hline Negative & 71 & & & & \\
\hline $\begin{array}{l}\text { Note: } \text { Values are given as mea } \\
N S=\text { Not significant } \\
N A=\text { Not applicable } \\
p<0.01 \text { pregnancy failure gro } \\
\text { T test }\end{array}$ & up compared wit & $\mathrm{h}$ the clinical preg & gnancy group, ar & lyzed with & dent's \\
\hline
\end{tabular}



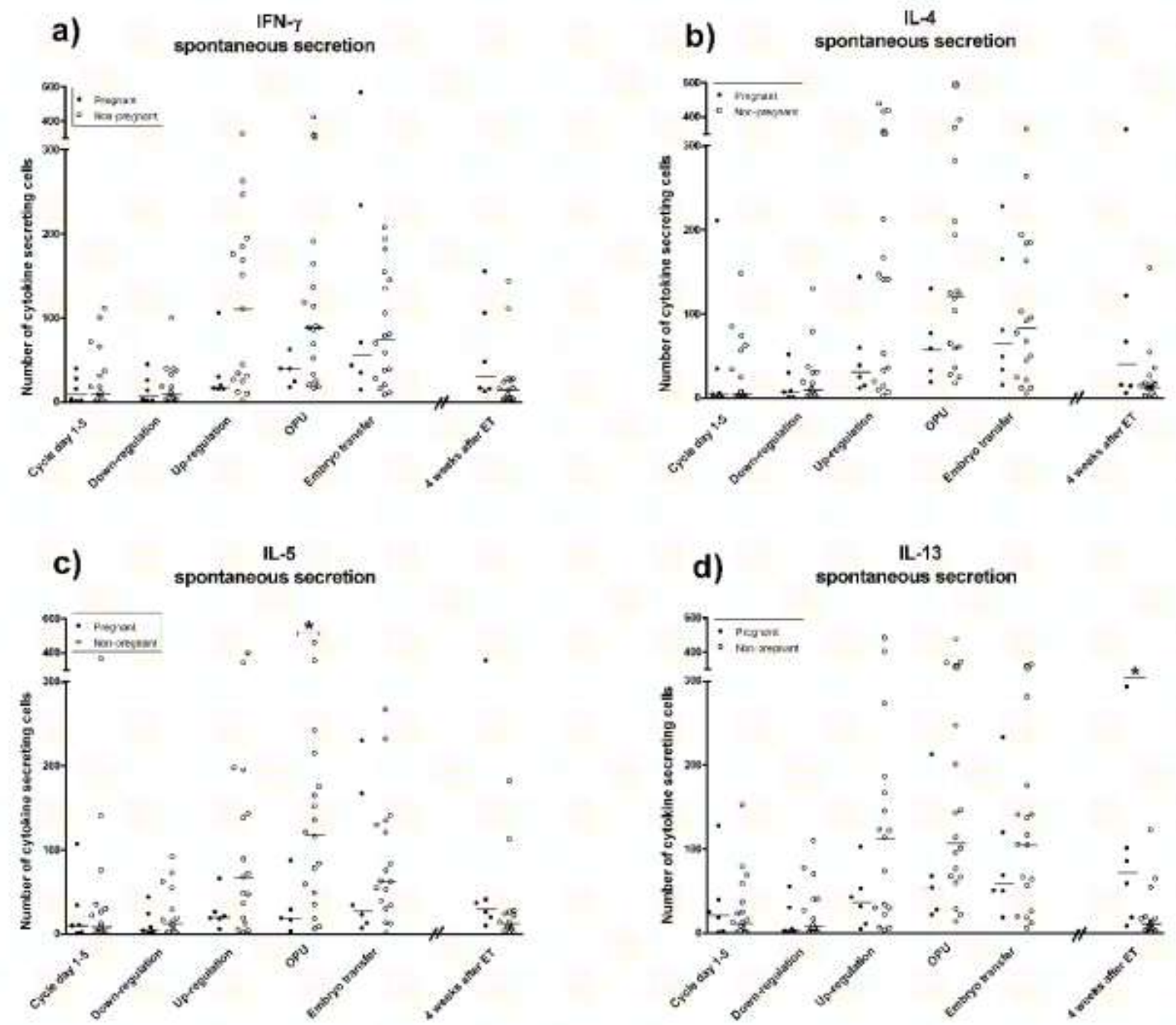

Fig. 2. The number of spontaneously IFN- $\gamma-$, IL-4-, IL-5- and IL-13-secreting cells in pregnant and non-pregnant women. Individual and median values are shown. $p<0.05$ from Mann Whitney U test is indicated (*).

None of the variables included in the logistic regression analysis, i. e. the number of IFN- $\gamma-$, IL-4-, IL-5-, IL-12- and IL-13-secreting cells or the levels of IFN- $\gamma$, IL-4, IL-10, IL12, IL-17, GM-CSF and TNF, had any significant effect on the probability to become pregnant after IVF treatment. In general, the $95 \%$ confidence intervals for the odds ratios were rather well defined with values close to 1 (data not shown). 
IFN-y
a) paternal antigen induced secretion

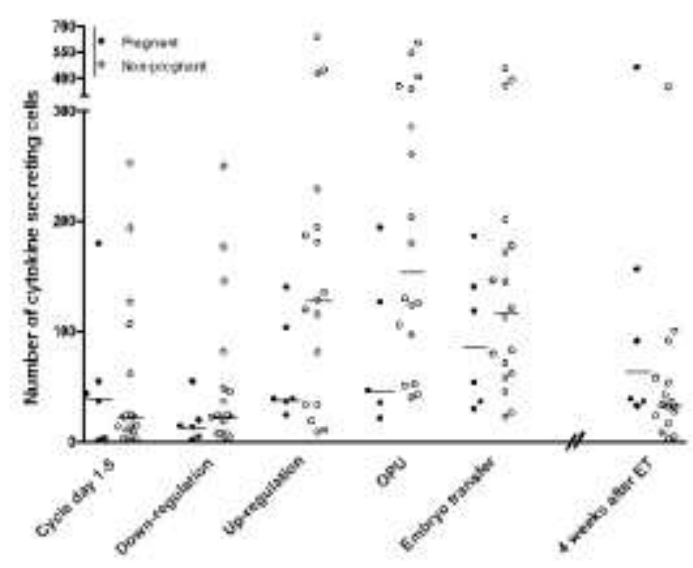

C) paternal antigen induced socrotion

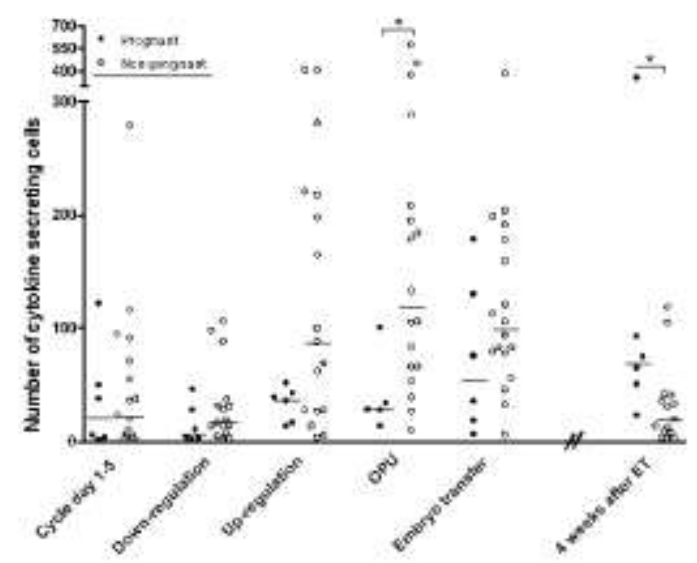

b) paternal antigen induced secretion

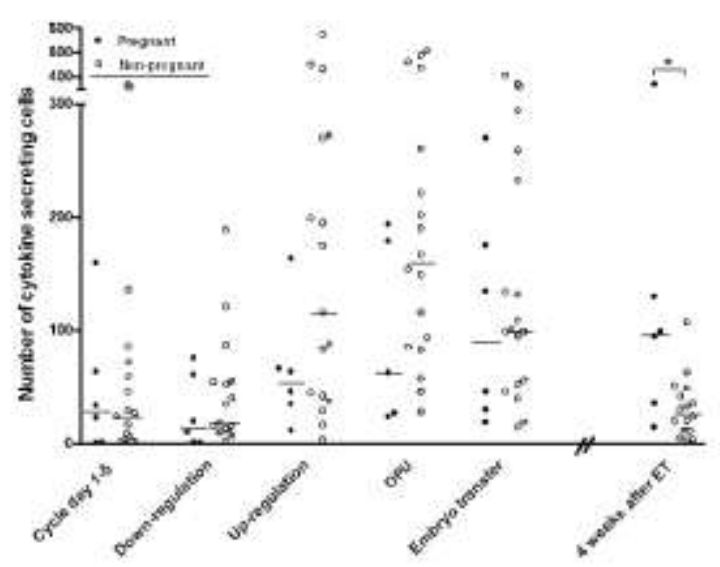

d) paternal antigen induced secretion

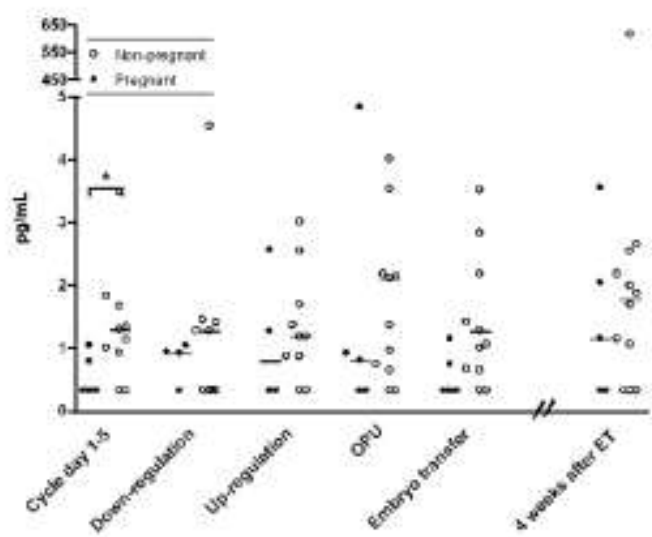

Fig. 3. The number of paternal antigen induced IFN- $\gamma$ - (a), IL-4- (b) and IL-5- (c) secreting cells and IL-4 concentrations in supernatants (d) in pregnant and non-pregnant women. Individual values, median values and $\mathrm{p}<0.05$ from Mann Whitney $U$ test is indicated (*).

\subsection{Changes in cytokine secretion during IVF treatment}

All women, regardless of pregnancy outcome, were investigated for changes caused by the hormonal treatment used during IVF (Fig. 4). There was an increase in the fold change of spontaneously IFN- $\gamma$-, IL-4-, IL-5-, IL-12- and IL-13-secreting cells at the times of upregulation, OPU and ET compared with cycle day 1-5 and compared with down-regulation. 
The number of IL-13-secreting cells was also increased at the time of OPU compared with upregulation, and decreased at the time of ET as compared with the time of OPU.

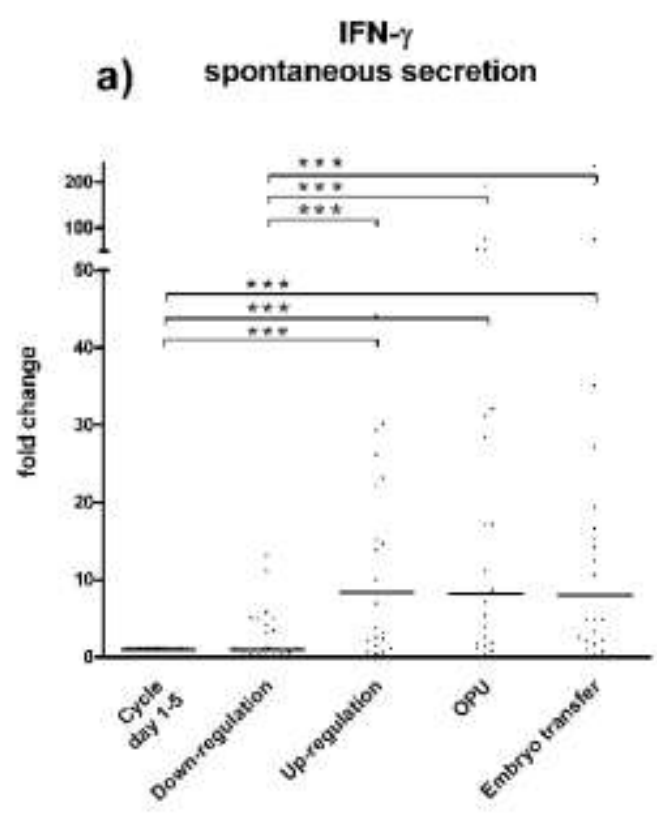

IL-5

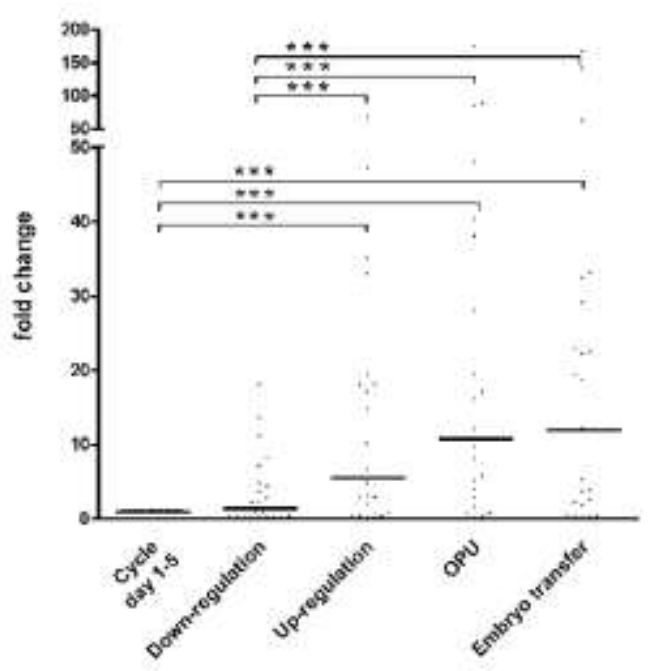

b) spontaneous secretion

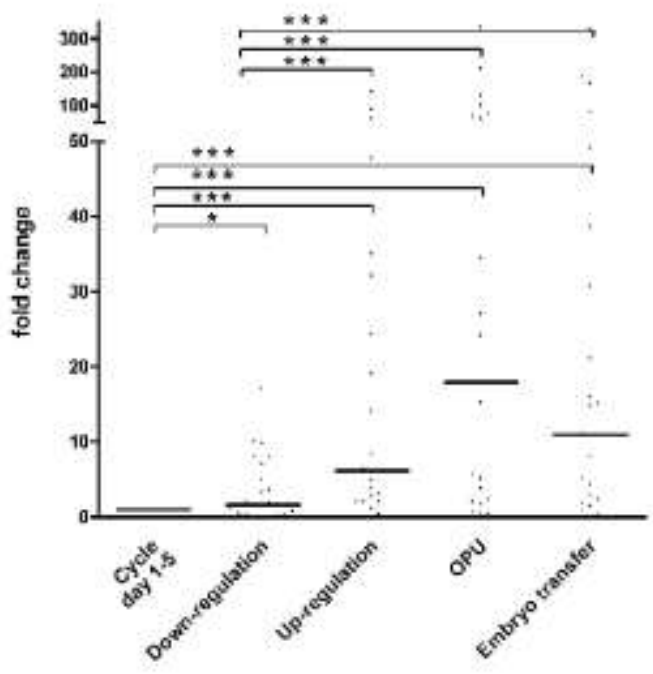

IL-13

d) spontaneous secretion

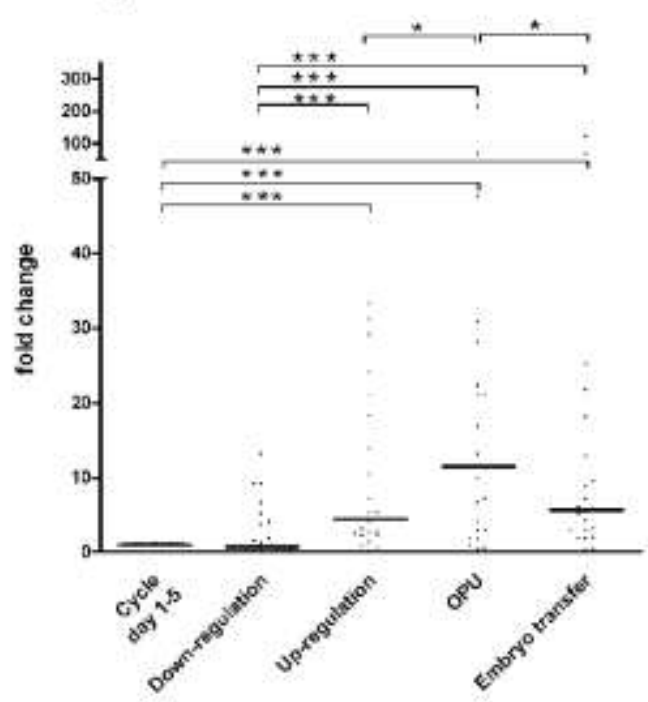

Fig. 4. Fold change in the number of spontaneously IFN- $\gamma-$, IL-4-, IL-5- and IL-13-secreting cells in all women, regardless of pregnancy outcome. Individual values and the median values of all individuals' fold change compared with cycle day 1-5 are shown. $p<0.05$ from Wilcoxon signed ranks test is indicated $\left(^{*}\right), p<0.01$ is indicated $(* *)$, and $p<0.001$ is indicated $(* * *)$. 
The statistically significant differences in fold change regarding the number of paternal antigen-induced IFN- $\gamma$-, IL-4- and IL-5-secreting cells included an increase at the times of upregulation, OPU and ET compared with cycle day 1-5 (Fig. 5) and also compared with downregulation. A decrease in the number of paternal antigen-induced IFN- $\gamma$-secreting cells was observed at the time of ET as compared with the time of OPU.
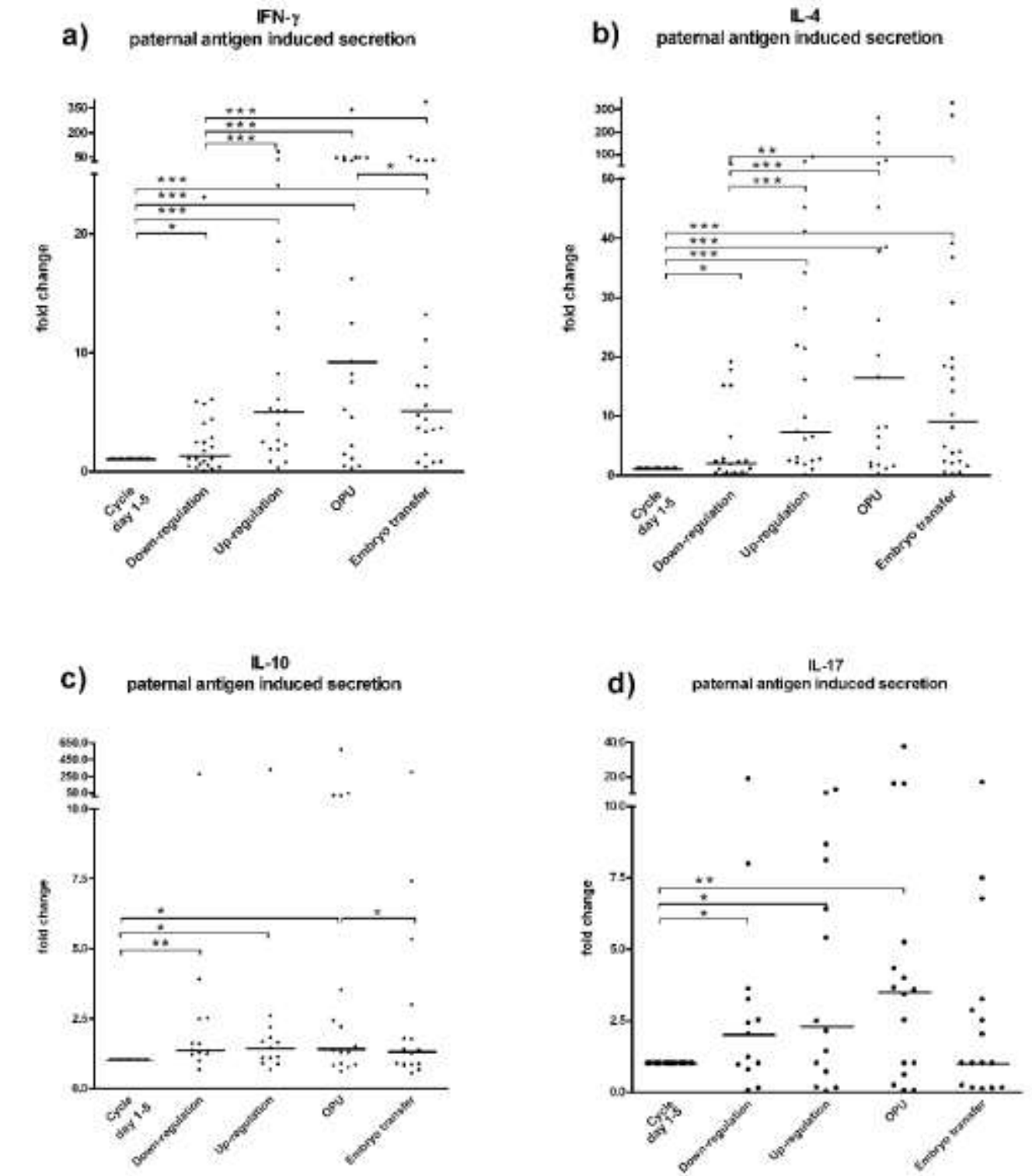

Fig. 5. Fold change in the number of paternal antigen induced IFN- $\gamma-$ (a) and IL-4- (b) secreting cells and concentrations of IL-10 (c) and IL-17 (d) in cell supernatants in all women, regardless of pregnancy outcome. Individual values and median values of all individuals' fold change compared with cycle day 1-5 are shown. $\mathrm{p}<0.05$ from Wilcoxon signed ranks test is indicated $(*)$. 
The fold change of paternal antigen-induced IL-10 and IL-17 secretion in supernatants was higher at the times of down-regulation, up-regulation and OPU compared with cycle day 1-5 (Fig. 5). Regarding IL-10, the secretion was also higher 4 weeks after ET compared with cycle day 1-5, and lower at ET compared with OPU (Fig. 5). The fold change of paternal antigen-induced IFN- $\gamma$ secretion was higher at the times of OPU, ET and 4 weeks after ET compared with cycle day 1-5 (Fig. 5). The levels of TNF and GM-CSF were similar throughout the course of IVF treatment and no differences in fold change were observed.

\section{Discussion}

Several observations suggest that Th1 cytokines are harmful to human pregnancy and may lead to pregnancy loss as early as at implantation (Kwak-Kim et al., 2003; Kalu et al., 2008; Hudic and Fatusic, 2009). Furthermore, although less studied, Th17-like immunity has been associated with recurrent miscarriage (Wang et al., 2010a; Wang et al., 2010b). We therefore examined whether an unsuccessful outcome of IVF in women with unexplained infertility was associated with a paternal antigen-specific Th1 and Th17 bias and if differences in cytokine responses could predict the IVF outcome. However, neither Th1-, Th2- nor Th17associated cytokine responses had any predictive value regarding IVF outcome. Other studies have reported factors with a predictive value on IVF outcome, e.g. IL-18 (Ledee-Bataille et al., 2004b); IL-10 and TNF (Boomsma et al., 2009); and IL-1ß (Bonetti et al., 2010). In these studies, cytokine levels were measured in uterine secretions or serum, while we use inactivated paternal cells as a proxy for allogeneic fetal cells to investigate the maternal peripheral responses toward fetal antigens (Ekerfelt et al., 1997). Furthermore, as the cytokine secretion by peripheral cells measured in the current study may not necessarily reflect local cytokine patterns (Ekerfelt et al., 2002b), local cytokine responses in the two groups of women may still differ. The present study did not investigate endometrial factors, which 
might be of greater importance than the peripheral immune response since a receptive endometrium is required for implantation and mediated by immune cells, cytokines, growth factors and adhesions molecules (Dimitriadis et al., 2005; van Mourik et al., 2009).

Although the present study found that none of the cytokines had any significant effect on the probability to become pregnant after IVF treatment, the possibility of using these cytokines in a larger study to predict IVF outcome cannot be excluded. The rationale for using ELISpot was that it is a sensitive method for IL-4 detection (Ekerfelt et al., 2002a). However, although more sensitive, especially regarding the quantification of IL-4, ELISpot would not be the method of choice in a larger study. A power analysis based on the results of the present pilot study, taking into account the large variability, indicates that a much larger sample size would be required. On the other hand, the multiplex assay has far less variability and would require more manageable sample sizes (ca 120 women to obtain a power of $80 \%$ and a detectable difference of three units). These calculations were made by dimensioning the test sample based on $\mathrm{T}$ test for two test samples, and subsequently correcting the calculations with the Pitman Efficiency coefficient of 0.955 .

We did observe a higher number of spontaneously IL-13- and paternal antigen-induced IL-4- and IL-5-secreting cells in the pregnant women than the non-pregnant women four weeks after ET. The finding of higher numbers of Th2 cytokine secreting cells in pregnant than non-pregnant women is in line with our previous findings (Matthiesen et al., 1998; Matthiesen et al., 2003) and in support of pregnancy as a Th2 phenomenon at the systemic level (Wegmann et al., 1993). In contrast, we found lower paternal antigen-induced IL-4 and IL-5 responses in the pregnant group than the non-pregnant group, at cycle day 1-5 for IL-4 and at OPU for IL-5. Later pregnancy was also associated with a lower number of spontaneously IL-5 secreting cells at the time of OPU. The significance of these findings is 
unclear and should be interpreted with caution, as the present study did not identify any predictive markers.

The power of this pilot study may not be statistically valid, considering the small number of subjects and the large number of variables tested. However, the well defined 95\% confidence intervals for the odds ratios suggest that the different variables do not affect the probability to become pregnant after IVF treatment. An insufficient number of samples or an inadequately designed study would have generated very wide confidence intervals.

The study design also allowed us to evaluate the hormonal influence on cytokine secretion during IVF treatment, suggesting a general stimulatory influence. The majority of the cytokines reached their peak levels at the time of OPU, coinciding with the maximal levels of FSH and HCG. In support of our findings, previous studies have found a gradual increase of serum macrophage colony-stimulating factor (M-CSF) and granulocyte colonystimulating factor (G-CSF) throughout ovarian stimulation in IVF cycles (Nishimura et al., 1998; Salmassi et al., 2005; Salmassi et al., 2010). IFN- $\gamma$, IL-4 and TNF have been studied after lymphocyte activation with PMA/ionomycin before and after ovarian stimulation (Kalu et al., 2008), and IL-10 has been analyzed in serum during IVF treatment (Wu et al., 2001). The influence of IVF hormonal treatment on IL-5, IL-12, IL-13, IL-17 and GM-CSF has, to the best of our knowledge, not been studied longitudinally before, however. In contrast to these in vivo studies, stimulatory effects of FSH and HCG on lymphocyte cytokine secretion have not been found in in vitro studies. FSH and HCG in combination reduced IFN- $\gamma$ production and T cell proliferation (Carbone et al., 2010), whereas HCG had no effect on the cytokine production of antigen-specific T cell lines and clones (Piccinni et al., 1995).

In conclusion, the results of the present study do not support our hypothesis of a more pronounced peripheral Th1 and Th17 deviation towards paternal antigens in infertile women with an unsuccessful as compared with a successful outcome of IVF, although this is based on 
a small number of observations. Thus, a larger study should be conducted to confirm this conclusion. The findings of a higher number of IL-4-, IL-5- and IL-13-secreting cells in pregnant than non-pregnant women corroborate the hypothesis of a Th2 deviation occurring during normal pregnancy. 


\section{Acknowledgements}

We would like to thank Olle Eriksson, Department of Mathematics, Division of Statistics, Linköping University, Sweden, and Karl Wahlin, Department of Computer and Information Science, Division of Statistics, Linköping University, Sweden, for invaluable help with statistical methods and analysis; the couples that participated in the study; the staff at the Reproductive Medicine Centre; and research nurse Lotta Lindh-Åstrand. 


\section{References}

Bonetti, T.C., Salomao, R., Brunialti, M., Braga, D.P., Borges, E., Jr.,Silva, I.D., 2010. Cytokine and hormonal profile in serum samples of patients undergoing controlled ovarian stimulation: interleukin-1beta predicts ongoing pregnancy. Hum Reprod 25, 2101-2106.

Boomsma, C.M., Kavelaars, A., Eijkemans, M.J., Lentjes, E.G., Fauser, B.C., Heijnen, C.J., et al., 2009. Endometrial secretion analysis identifies a cytokine profile predictive of pregnancy in IVF. Hum Reprod 24, 1427-1435.

Böttcher, M.F., Bjurstrom, J., Mai, X.M., Nilsson, L.,Jenmalm, M.C., 2003. Allergen-induced cytokine secretion in atopic and non-atopic asthmatic children. Pediatr Allergy Immunol 14, 345-350.

Carbone, F., Procaccini, C., De Rosa, V., Alviggi, C., De Placido, G., Kramer, D., et al., 2010. Divergent immunomodulatory effects of recombinant and urinary-derived FSH, LH, and hCG on human CD4+ T cells. J Reprod Immunol 85, 172-179.

Commins, S.P., Borish, L.,Steinke, J.W., 2010. Immunologic messenger molecules: cytokines, interferons, and chemokines. J Allergy Clin Immunol 125, S53-72.

Dimitriadis, E., White, C.A., Jones, R.L.,Salamonsen, L.A., 2005. Cytokines, chemokines and growth factors in endometrium related to implantation. Hum Reprod Update 11, 613-630.

Ekerfelt, C., Ernerudh, J.,Jenmalm, M.C., 2002a. Detection of spontaneous and antigeninduced human interleukin-4 responses in vitro: comparison of ELISPOT, a novel ELISA and real-time RT-PCR. J Immunol Methods 260, 55-67.

Ekerfelt, C., Lidstrom, C., Matthiesen, L., Berg, G., Sharma, S.,Ernerudh, J., 2002b. Spontaneous secretion of interleukin-4, interleukin-10 and interferon-gamma by first trimester decidual mononuclear cells. Am J Reprod Immunol 47, 159-166.

Ekerfelt, C., Matthiesen, L., Berg, G.,Ernerudh, J., 1997. Paternal leukocytes selectively increase secretion of IL-4 in peripheral blood during normal pregnancies: demonstrated by a novel one-way MLC measuring cytokine secretion. Am J Reprod Immunol 38, 320326.

Ernerudh, J., Berg, G.,Mjosberg, J., 2011. Regulatory T helper cells in pregnancy and their roles in systemic versus local immune tolerance. Am J Reprod Immunol 66 Suppl 1, 3143.

Ginsburg, E.S., Xiao, L., Gargiulo, A.R., Kung, F.T., Politch, J.A., Schust, D.J., et al., 2005. T-helper 2 and 3 type immunity to trophoblast in successful in vitro fertilization-embryo transfer. Fertil Steril 83, 1659-1664.

Hudic, I.,Fatusic, Z., 2009. Progesterone - induced blocking factor (PIBF) and Th(1)/Th(2) cytokine in women with threatened spontaneous abortion. J Perinat Med 37, 338-342.

Inagaki, N., Stern, C., McBain, J., Lopata, A., Kornman, L., Wilkinson, D., 2003. Analysis of intra-uterine cytokine concentration and matrix-metalloproteinase activity in women with recurrent failed embryo transfer. Hum Reprod 18, 608-615.

Kalu, E., Bhaskaran, S., Thum, M.Y., Vishwanatha, R., Croucher, C., Sherriff, E., et al., 2008. Serial estimation of Th1:Th2 cytokines profile in women undergoing in-vitro fertilization-embryo transfer. Am J Reprod Immunol 59, 206-211.

Kwak-Kim, J.Y., Chung-Bang, H.S., Ng, S.C., Ntrivalas, E.I., Mangubat, C.P., Beaman, K.D., et al., 2003. Increased $\mathrm{T}$ helper 1 cytokine responses by circulating $\mathrm{T}$ cells are present in women with recurrent pregnancy losses and in infertile women with multiple implantation failures after IVF. Hum Reprod 18, 767-773.

Ledee-Bataille, N., Dubanchet, S., Coulomb-L'hermine, A., Durand-Gasselin, I., Frydman, R.,Chaouat, G., 2004a. A new role for natural killer cells, interleukin (IL)-12, and IL-18 in repeated implantation failure after in vitro fertilization. Fertil Steril 81, 59-65. 
Ledee-Bataille, N., Olivennes, F., Kadoch, J., Dubanchet, S., Frydman, N., Chaouat, G., et al., 2004b. Detectable levels of interleukin-18 in uterine luminal secretions at oocyte retrieval predict failure of the embryo transfer. Hum Reprod 19, 1968-1973.

Lin, H., Mosmann, T.R., Guilbert, L., Tuntipopipat, S.,Wegmann, T.G., 1993. Synthesis of T helper 2-type cytokines at the maternal-fetal interface. J Immunol 151, 4562-4573.

Makhseed, M., Raghupathy, R., Azizieh, F., Omu, A., Al-Shamali, E.,Ashkanani, L., 2001. Th1 and Th2 cytokine profiles in recurrent aborters with successful pregnancy and with subsequent abortions. Hum Reprod 16, 2219-2226.

Matthiesen, L., Ekerfelt, C., Berg, G.,Ernerudh, J., 1998. Increased numbers of circulating interferon-gamma- and interleukin-4-secreting cells during normal pregnancy. Am J Reprod Immunol 39, 362-367.

Matthiesen, L., Khademi, M., Ekerfelt, C., Berg, G., Sharma, S., Olsson, T., et al., 2003. Insitu detection of both inflammatory and anti-inflammatory cytokines in resting peripheral blood mononuclear cells during pregnancy. J Reprod Immunol 58, 49-59.

Milner, J.D., 2011. IL-17 producing cells in host defense and atopy. Curr Opin Immunol 23, 784-788.

Ng, S.C., Gilman-Sachs, A., Thaker, P., Beaman, K.D., Beer, A.E.,Kwak-Kim, J., 2002. Expression of intracellular Th1 and Th2 cytokines in women with recurrent spontaneous abortion, implantation failures after IVF/ET or normal pregnancy. Am J Reprod Immunol 48, 77-86.

Nishimura, K., Tanaka, N., Kawano, T., Matsuura, K.,Okamura, H., 1998. Changes in macrophage colony-stimulating factor concentration in serum and follicular fluid in invitro fertilization and embryo transfer cycles. Fertil Steril 69, 53-57.

Persson, M., Ekerfelt, C., Ernerudh, J., Matthiesen, L., Jenmalm, M., Jonsson, Y., et al., 2008. Increased circulating paternal antigen-specific IFN-gamma- and IL-4-secreting cells during pregnancy in allergic and non-allergic women. J Reprod Immunol 79, 70-78.

Peterson, R.A., 2012. Regulatory T-Cells: Diverse Phenotypes Integral to Immune Homeostasis and Suppression. Toxicol Pathol.

Piccinni, M.P., Beloni, L., Livi, C., Maggi, E., Scarselli, G.,Romagnani, S., 1998. Defective production of both leukemia inhibitory factor and type 2 T-helper cytokines by decidual T cells in unexplained recurrent abortions. Nat Med 4, 1020-1024.

Piccinni, M.P., Giudizi, M.G., Biagiotti, R., Beloni, L., Giannarini, L., Sampognaro, S., et al., 1995. Progesterone favors the development of human T helper cells producing Th2-type cytokines and promotes both IL-4 production and membrane CD30 expression in established Th1 cell clones. J Immunol 155, 128-133.

Raghupathy, R., Makhseed, M., Azizieh, F., Hassan, N., Al-Azemi, M.,Al-Shamali, E., 1999. Maternal Th1- and Th2-type reactivity to placental antigens in normal human pregnancy and unexplained recurrent spontaneous abortions. Cell Immunol 196, 122-130.

Sacks, G.P., Redman, C.W.,Sargent, I.L., 2003. Monocytes are primed to produce the Th1 type cytokine IL-12 in normal human pregnancy: an intracellular flow cytometric analysis of peripheral blood mononuclear cells. Clin Exp Immunol 131, 490-497.

Salmassi, A., Mettler, L., Jonat, W., Buck, S., Koch, K.,Schmutzler, A.G., 2010. Circulating level of macrophage colony-stimulating factor can be predictive for human in vitro fertilization outcome. Fertil Steril 93, 116-123.

Salmassi, A., Schmutzler, A.G., Schaefer, S., Koch, K., Hedderich, J., Jonat, W., et al., 2005. Is granulocyte colony-stimulating factor level predictive for human IVF outcome? Hum Reprod 20, 2434-2440.

Sanchez-Cuenca, J., Martin, J.C., Pellicer, A.,Simon, C., 1999. Cytokine pleiotropy and redundancy--gp130 cytokines in human implantation. Immunol Today 20, 57-59. 
Simon, C., Moreno, C., Remohi, J.,Pellicer, A., 1998. Cytokines and embryo implantation. J Reprod Immunol 39, 117-131.

van Mourik, M.S., Macklon, N.S.,Heijnen, C.J., 2009. Embryonic implantation: cytokines, adhesion molecules, and immune cells in establishing an implantation environment. J Leukoc Biol 85, 4-19.

Wang, W.J., Hao, C.F., Qu, Q.L., Wang, X., Qiu, L.H.,Lin, Q.D., 2010a. The deregulation of regulatory $\mathrm{T}$ cells on interleukin-17-producing $\mathrm{T}$ helper cells in patients with unexplained early recurrent miscarriage. Hum Reprod 25, 2591-2596.

Wang, W.J., Hao, C.F., Yi, L., Yin, G.J., Bao, S.H., Qiu, L.H., et al., 2010b. Increased prevalence of $\mathrm{T}$ helper 17 (Th17) cells in peripheral blood and decidua in unexplained recurrent spontaneous abortion patients. J Reprod Immunol 84, 164-170.

Wegmann, T.G., Lin, H., Guilbert, L.,Mosmann, T.R., 1993. Bidirectional cytokine interactions in the maternal-fetal relationship: is successful pregnancy a $\mathrm{TH} 2$ phenomenon? Immunol Today 14, 353-356.

Wu, M.Y., Chen, H.F., Chen, S.U., Chao, K.H., Yang, Y.S.,Ho, H.N., 2001. Increase in the production of interleukin-10 early after implantation is related to the success of pregnancy. Am J Reprod Immunol 46, 386-392. 